\title{
STATISTICAL MODELLING OF THE IMPACT OF DIABETES ON THE RISK OF HOSPITALIZATION
}

\author{
BEATA ZMYŚLONA \\ Wrocław University of Economics, Faculty of Management, Information Systems and Finance, \\ Department of Statistics, Komandorska Street. 118/120, 53-345 Wrocław \\ email: beata.zmyslona@ue.wroc.pl
}

\begin{abstract}
The research problem concerns the issue of modelling the impact of diabetes on the risk of hospitalization. More frequent hospitalizations affect the growth of medical costs. The influence of diabetes on expenditures connected with higher risk of hospitalization will be estimated by means of attributable and relative risk. The risk of re-hospitalization will be modelled by logistic regression model with iteration effects. The demographic variable (such as age and sex of the patient), variables related to the health status of the patient (cooccurrence of other disease entities, interactions between the occurrence of cardiovascular diseases and diabetes), and the variables connected with the treatment process (repeatability of hospitalization) will be used. In particular, the impact of diabetes on the cardiovascular diseases treatment cost (especially diabetic complications) will be analyzed. Expenditures on diabetes incurred by the public payer in Poland, namely the National Health Fund, will be taken into account. The NHF is the main public finance sector entity which activity is directly related to the health care of diabetics. On the basis of relative risk the hypothetical saved cost can be determined.
\end{abstract}

Key words: hypothetical saved cost, attributable risk, relative risk, ordered logit regression model with interaction effects.

DOI: 10.15611/amse.2014.17.33

\section{Introduction}

In recent decades diabetes has become a pandemics, which has an impact not only on the health status of the society, but also on the economy. In 2012, about $7 \%$ of the Polish population had diabetes. In Poland, it is estimated that the treatment of diabetes and its complications accounts for almost $10 \%$ of public spending on health care and the share of expenditures in the total cost will be increased in the years to come (KOZYRA $C$., ZMYŚLONA B. 2012, IDF ATLAS 2013).

According to the estimates, cardiovascular diseases pose $75 \%$ of the benefits cost provided due to diabetes complication treatment. Because of an impact of diabetes on the risk of complications, it affects indirectly the increase of the cardiovascular diseases treatment cost. A particularly troublesome problem is determination of the share of the cost. It would be a wrong solution not to take into account the cost of the expenses generated by diabetes or incorporate them in their entirety. Determination of a diabetes impact on cardiovascular disease treatment costs will be associated with the estimation of hypothetically saved cost after eliminating diabetes in a population. This effect will be manifested not only in increasing treatment cost, but also in increasing the risk of hospitalization and rehospitalization among diabetics compared to the rest of the population. A hospitalization risk will be modelled using relative and attributable risks. On the basis of estimated risk, it is 


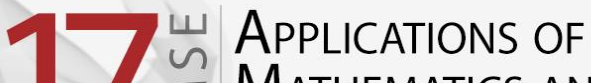 \\ Mathematics and Statistics \\ IN ECONOMICS \\ International Scientific Conference | Poland • 27-31 August 2014}

possible to determine the share of the cost of hospital treatment of other types of diseases caused by diabetes. This share may be used to estimate the hypothetical saved cost after elimination of diabetes.

\section{Modelling the impact of diabetes on hospitalization risk}

The problem of estimating the effect of diabetes on the risk of hospitalization for cardiovascular diseases will be considered. The impact of diabetes on increased risk of hospitalization and treatment costs will be estimated using relative and attributable risks.

Let $X$ denote the random variable used to model the hospitalization risk due to cardiovascular disease, where

$$
X=\left\{\begin{array}{lc}
0 & \text { in case of the lack of hospitalization, } \\
1 & \text { in case of hospitalization. }
\end{array}\right.
$$

Let's define an indicator variable $\mathrm{Z}$, where

$$
Z=\left\{\begin{array}{cc}
0 & \text { in case of non-diabetes, } \\
1 & \text { in case of diabetes. }
\end{array}\right.
$$

Let's assume the following sings. Let $P(X=1)$ denote the probability of hospitalization due to cardiovascular diseases in population, $P(X=1 \mid Z=1)$ - the probability of hospitalization for diabetics and $P(X=1 \mid Z=0)$ - hypothetical probability of hospitalization in population without diabetes as an exposed factor.

The attributable risk $A R$ that takes into account the impact of diabetes on the rate of hospitalization is indicated by the formula (BENICHOU J. 2007)

$$
A R=\frac{P(X=1)-P(X=1 \mid Z=0)}{P(X=1)} .
$$

The risk determines the proportion of the rate of hospitalization which would be reduced after elimination of diabetes. The probability of hospitalization can be represented as the sum of the probabilities associated with hospitalization of diabetics and non-diabetics in the following manner

$$
P(X=1)=P(X=1 \mid Z=1) P(Z=1)+P(X=1 \mid Z=0)(1-P(Z=1)),
$$

where $P(Z=1)$ is defined as the probability of diabetes prevalence. The quotient of the conditional probabilities of hospitalization for diabetics and non-diabetics can be defined using the relative risk in the following manner

$$
R R=\frac{P(X=1 \mid Z=1)}{P(X=1 \mid Z=0)} .
$$

Taking into account the decomposition of $P(X=1)$ by means of expression (2) and the definition of relative risk (3), a counter of the formula for the attributable risk is expressed as

$$
P(X=1 \mid Z=1) P(Z=1)\left(1-\frac{1}{R R}\right) .
$$

The probability of hospitalization for diabetics can be expressed by Bayes' formula in the following way 


\section{崩 APPLICATIONS OF

$$
P(X=1 \mid Z=1)=\frac{P(Z=1 \mid X=1) P(X=1)}{P(Z=1)} .
$$

After replacing (5) in formula (4), the counter assigned risk (1) can be expressed as

$$
P(X=1) P(Z=1 \mid X=1)\left(1-\frac{1}{R R}\right) .
$$

Finally, the attributable risk depends on the relative risk and the probability of an occurrence of diabetes among hospitalized patients, and it is expressed by the following formula

$$
A R=\frac{R R-1}{R R} P(Z=1 \mid X=1) .
$$

Proportion of hospitalization expenditures in connection with the occurrence of diabetes is determined as

$$
A P=\frac{(R R-1)}{R R} .
$$

The term (8) represents the proportion of the hypothetical hospital treatment cost of other diseases caused by diabetes

\section{Average annual cost of hospital treatment for diabetics and non-diabetics}

The analysis s carried out on a group of hospitalized patients in all hospitals in the Lower Silesia, for whom the primary diagnosis was one of the following diseases: hypertensive disease, ischemic disease or atherosclerosis (Database From National Health Fund 2012).

The following variables are used in the analysis:

$T_{1}-$ sex of patient ( 0 for women, 1 for men),

$T_{2}$ - age of patient (divided into five groups according to the frequencies of occurrence of hospitalization for the diseases in population of diabetics and non-diabetics: 1 for 20-50 years old, 2 for 50-60, 3 for 60-70, 4 for 70-80, 5 above 80),

$Z$ - incidence of diabetes ( 0 for no, 1 for yes),

$D_{1}$ - incidence of hypertensive diseases (a group of diseases classified by the International Classification of Diseases (ICD-10) using code from I10 to I15 (0 for no, 1 for yes),

$D_{2}$ - incidence of ischemic heart disease (a group of diseases classified by ICD-10 using code from I20 to I24 (0 for no, 1 for yes),

$D_{3}$ - incidence of atherosclerosis (a group of diseases classified by ICD-10 using code I70 (0 for no, 1 for yes).

The number of hospitalized patients due to the cardiovascular diseases with and without diabetes was determined on the basis of individual data from the Lower Silesia Department of the National Health Fund. Patients were identified using the coded numbers of the Universal Electronic System for Registration of the Population (Social Security). Let's denote a number of patients with diabetics in $j$-th age group, hospitalized due to $k$-th cardiovascular disease by $n_{i j k 1}$ (the index $i$ is connected with sex of patient and index 1 with coexistence of diabetes). In the same manner a number of patient without diabetes is denoted by $n_{i j k 0}$.

Due to the fact that the re-hospitalization risk was also estimated in the further analysis, a database of hospitalized patients was created as follows. The primary investigation period was between July, 1 in 2009 and June, 30 in 2010. In case of any patient for whom the first 


\section{A Apulations of \\ Mathematics and Statistics \\ IN ECONOMICS \\ International Scientific Conference | Poland • 27-31 August 2014}

hospitalization started in that period (01.07.2009 to 30.06.2010), the annual history of all hospitalization was analyzed, and so the final date was 30.06.2011. 20128 patients were hospitalized during the aforementioned period due to cardiovascular disease.

Due to the presence of outliers, a median was used to compare the average level of treatment cost. The medians of cost of treating one patient for women and men according to the type of disease, age group and co-morbidity of diabetes in shown in Table 1.

Table 1 Annual median cost of hospitalization per patient (in PLN).

\begin{tabular}{|c|c|c|c|c|c|c|c|}
\hline & \multirow[b]{2}{*}{ Age group } & \multicolumn{2}{|c|}{ Hypertensive diseases } & \multicolumn{2}{|c|}{ Ischemic heart disease } & \multicolumn{2}{|c|}{ Atherosclerosis } \\
\hline & & $\begin{array}{c}\text { non- } \\
\text { diabetic }\end{array}$ & diabetic & $\begin{array}{c}\text { non- } \\
\text { diabetic }\end{array}$ & Diabetic & $\begin{array}{c}\text { non- } \\
\text { diabetic }\end{array}$ & Diabetic \\
\hline \multirow{5}{*}{$\begin{array}{l}\overline{0} \\
\text { है } \\
3^{2}\end{array}$} & $20-50$ & 1428.00 & 4080.00 & 12036.00 & 12040.00 & 1836.00 & 2448.00 \\
\hline & $50-60$ & 1428.00 & 1440.00 & 12036.00 & 13515.00 & 2040.00 & 3544.50 \\
\hline & $60-70$ & 1428.00 & 1440.00 & 12342.00 & 13540.50 & 2206.28 & 2448.00 \\
\hline & $70-80$ & 1428.00 & 1500.00 & 12036.00 & 12150.00 & 2448.00 & 3468.00 \\
\hline & $>80$ & 1428.00 & 1428.00 & 10659.00 & 12036.00 & 2448.00 & 2600.00 \\
\hline \multirow{5}{*}{$\sum_{\Sigma}^{\tilde{E}}$} & $20-50$ & 1428.00 & 1440.00 & 13515.00 & 15045.00 & 2325.10 & 12444.00 \\
\hline & $50-60$ & 1428.00 & 1428.00 & 13515.00 & 13600.00 & 4080.00 & 6120.00 \\
\hline & $60-70$ & 1428.00 & 1428.00 & 12648.00 & 13515.00 & 3213.00 & 7140.00 \\
\hline & $70-80$ & 1428.00 & 2958.00 & 12036.00 & 12342.00 & 2448.00 & 4896.00 \\
\hline & $>80$ & 1428.00 & 1460.00 & 12036.00 & 12036.00 & 2448.00 & 2448.00 \\
\hline
\end{tabular}

Source: Own elaboration using Statistica 10.0.

The costs of treatment for women and men with diabetes are (with a few exceptions) significantly higher for all age groups. Differences between costs for diabetics and nondiabetics are more visible for atherosclerosis and ischemic heart disease, especially for men. The detailed description of the database and presentation of methods of estimating a surplus treatment cost of diabetes are provided in the manuscript (ZMYŚLONA B. MANUSCRIPT).

In further considerations, we will assume that diabetes affects the growth of medical costs not only by increasing the average treatment cost, but also by augmenting other relevant factors, such as risk of hospitalization and re-hospitalization or risk of coexistence of other cardiovascular diseases. Modelling of the effect of diabetes on the risk of hospitalization and re-hospitalization will be presented in the next part of the paper.

\section{Estimation of relative and attributable risk connected with the impact of diabetes on hospitalization event}

Age and sex of a patient are determinants which influence both the risk of diabetes or/and the incidence of cardiovascular diseases and the risk of hospitalization due to their occurrence. Therefore, the attributable risk should be estimated in groups determined with regards to patient's age and gender. Diabetes affects the occurrence of certain types of diseases in different manners. For this reason, the attributable risk will be determined separately for each group of disease entities.

The effect of the interaction between the cardiovascular diseases will not be taken into account in the process hospitalization risk estimation. This results from the inability to assess the coexistence of these diseases in the remaining part of a population, except the hospitalized members. The procedure of calculating relative and attributable risks does not take into account population heterogeneity as a source of variability. In the analysis, the equal influence of such factors as genetic, environmental and behavioral on the diabetics and non-diabetics is assumed. Despite individual variation, it can be assumed that the average impact of these 
factors on individuals from particular age group is comparable in case of occurrence of diabetes as well as without it.

The numbers of diabetics and non-diabetics in particular demographic groups in population were established on the basis of data from two sources. Data on the size of the population by sex and age groups $\left(N_{i j}\right)$ was derived from (Yearbook of Polish Central Statistical Office 2011). The number of diabetics in particular demographic groups was calculated on the basis of the estimated diabetes prevalence rates $\hat{\kappa}_{j}$ for particular age groups included in the results of the research project $\left(\hat{\kappa}_{1}=0.012 ; \hat{\kappa}_{2}=0.024 ; \hat{\kappa}_{3}=0.084 ; \hat{\kappa}_{4}=0.134 ; \hat{\kappa}_{5}=0.185\right)$ (JANKOWSKI et al. 2012). In the project, diabetes prevalence rates were estimated for age groups determined with an accuracy of up to 10 years. For the purposes of the presented analysis, patients from 20 to 50 years of age were combined together in one group, which resulted from very sporadic hospitalizations in the age groups up to 40 years. The same procedure was used as for patients over 80 . For these two groups, the prevalence rates of diabetics were estimated using the weighted average on the basis of the size of the age groups. The number of hospitalized patients due to the cardiovascular diseases with and without diabetes in different age groups $\left(n_{i j k 1}\right.$ and $\left.n_{i j k 0}\right)$ was determined on the basis of described above data from the National Health Fund (Database From National Health Fund 2012). Diabetes prevalence rates among hospitalized people were estimated on the basis of this database, too. The term $\hat{p}_{(Z \mid X) i j k}$ denotes the prevalence rate of diabetics among hospitalized patients in $i$ th category of sex and $j$ th age group for $k$ th disease.

The relative risk was estimated based on the ratio of frequencies of diabetics and non diabetics belonging to one of demographic groups who were hospitalized due to one of the diseases. The following formula was used

$$
\hat{R R} R_{i j k}=\frac{\omega_{i j k 1}}{\omega_{i j k 0}}
$$

where $\omega_{i j k 1}=\frac{n_{i j k 1}}{\hat{\kappa}_{j} N_{i j}}$ and $\omega_{i j k 0}=\frac{n_{i j k 0}}{\left(1-\hat{\kappa}_{j}\right) N_{i j}}$ denote, respectively, the proportion of diabetics and non-diabetics from the $i$ th $(i=1,2$ - the index of sex $)$ and $j$ th $(j=1,2, \ldots, 5)$ group hospitalized due to the $k$ th $(k=1,2,3)$ vascular diseases.

The attributable risk is calculated on the basis of estimators of relative risk using formula (7), where the prevalence rate of diabetes among hospitalized patients is the estimator of probability $P(Z=1 \mid X=1)$. If the value of relative risk is bigger than 1 , it means that the cooccurrence of diabetes increases the risk of hospitalization. The attributable risk enables to specify the impact of diabetes on the increase of hospitalization risk. For this reason, the values of attributable risk are calculated only in case when the relative risk is bigger than 1 . Values of relative risk less than 1 indicate that the proportion of hospitalizations in particular age group with diabetes is lower than it would result from diabetes prevalence rate in this group.

The estimated values of the relative risk and the attributable are were presented in Table 2. Attributable risk value in case of relative risk being greater than 1 is interpreted as the proportion of hospitalization in the population that could be reduced if diabetes as a risk factor was eliminated. Higher values of relative risk appear among younger patients, both in men and women groups. For older age groups, despite the significant proportion of diabetics 


\section{7. \\ Mathematics and Statistics \\ IN ECONOMICS \\ International Scientific Conference | Poland • 27-31 August 2014}

among those hospitalized, the relative risk is less than 1 . This is due to the fact that diabetics with cardiovascular disease also have other complications such as cerebral atherosclerosis, diabetic foot, and other which are the major diagnosis. Diabetics with numerous complications, including the cardiovascular, have a shorter average life expectancy. It also reduces the impact of diabetes on the risk of hospitalization in older age groups.

The values of rate $A P(8)$ indicate the proportion of hospitalization expenditures in connection with the influence of diabetes on hospitalization risk. The values can be interpreted as a percentage of cardiovascular diseases treatment costs for diabetics, which can be attributed directly to diabetes as a risk factor. Due to the fact that the coefficient $A P$ depends on relative risk, high values are observed for younger patients.

Table 2. The estimators of relative and attributable risks and prevalence rates of diabetes among hospitalized patients.

\begin{tabular}{|c|c|c|c|c|c|c|}
\hline & Age group & $20-50$ & $50-60$ & $60-70$ & 70-80 & $>80$ \\
\hline \multicolumn{7}{|c|}{ I. Hypertensive disease } \\
\hline \multirow{4}{*}{ Men } & $R R$ & 4.4366 & 5.7725 & 1.2466 & 0.7715 & 0.2839 \\
\hline & $A R$ & 0.0407 & 0.1021 & 0.0203 & - & - \\
\hline & $A P$ & 0.7746 & 0.8268 & 0.1978 & - & - \\
\hline & $\hat{p}_{(Z \mid X)}$ & 0.0517 & 0.1235 & 0.1026 & 0.1067 & 0.0606 \\
\hline \multirow{4}{*}{ Women } & $R R$ & 4.5191 & 1.1145 & 0.8363 & 0.1432 & 0.5316 \\
\hline & $A R$ & 0.0265 & 0.0095 & - & - & - \\
\hline & $A P$ & 0.7787 & 0.1027 & - & - & - \\
\hline & $\hat{p}_{(Z \mid X)}$ & 0.0265 & 0.0927 & 0.1146 & 0.1272 & 0.0921 \\
\hline \multicolumn{7}{|c|}{ II. Ischemic Heart Disease } \\
\hline \multirow{4}{*}{ Men } & $R R$ & 3.3503 & 1.763 & 0.8665 & 0.5123 & 0.3845 \\
\hline & $A R$ & 0.0278 & 0.0179 & - & - & - \\
\hline & $A P$ & 0.7612 & 0.4329 & - & - & - \\
\hline & $\hat{p}_{(Z \mid X)}$ & 0.0396 & 0.0414 & 0.0736 & 0.0736 & 0.003 \\
\hline \multirow{4}{*}{ Women } & $R R$ & 7.2176 & 0.8496 & 0.6879 & 0.1019 & 0.555 \\
\hline & $A R$ & 0.0359 & - & - & - & - \\
\hline & $A P$ & 0.8614 & - & - & - & - \\
\hline & $\hat{p}_{(Z \mid X)}$ & 0.0417 & 0.0723 & 0.0963 & 0.0945 & 0.0959 \\
\hline \multicolumn{7}{|c|}{ III. Atherosclerosis } \\
\hline \multirow{4}{*}{ Men } & $R R$ & 3.2236 & 4.542 & 1.7057 & 0.9188 & 0.4796 \\
\hline & $A R$ & 0.0263 & 0.0759 & 0.0557 & - & - \\
\hline & $A P$ & 0.6898 & 0.7798 & 0.4137 & - & - \\
\hline & $\hat{p}_{(Z \mid X)}$ & 0.0381 & 0.0974 & 0.1346 & 0.1246 & 0.0988 \\
\hline \multirow{4}{*}{ Women } & $R R$ & 12.1031 & 1.0765 & 1.0663 & 0.1288 & 0.5660 \\
\hline & $A R$ & 0.0621 & 0.0064 & 0.0088 & - & - \\
\hline & $A P$ & 0.9174 & 0.0711 & 0.0622 & - & - \\
\hline & $\hat{p}_{(Z \mid X)}$ & 0.0677 & 0.0899 & 0.1416 & 0.1221 & 0.0981 \\
\hline
\end{tabular}

Source: Own elaboration. 


\section{出 APPLICATIONS OF \\ Mathematics and Statistics \\ IN ECONOMICS \\ International Scientific Conference | Poland • 27-31 August 2014}

\section{Modelling the re-hospitalization risk}

The method of the re-hospitalization risk modelling depends on the choice of aspect of rehospitalization, that is whether it is a one-off re-hospitalization or a number of rehospitalizations. In the present analysis, the model with the number of repeated hospitalization is considered on the basis of (Database From National Health Fund 2012). The structure of the number of subsequent hospitalizations takes shape as follows: $77.85 \%$ of patients was not re-hospitalized, $16.27 \%$ was re-hospitalized once, $4.16 \%$ - twice, and only $1.72 \%$ was re-hospitalized more than twice. The probability of a subsequent hospitalization during one year is modelled using the ordered logit regression with interactions (LIU, AGRESTI 2005). The Poisson regression models can also be used (HY, XIE, GOH 2014, LIM, LI, YU 2014, ZAMANI, ISMAIL 2014). Let's define the random variable $Y$ as

$$
Y=\left\{\begin{array}{l}
0 \quad \text { in case of lack of re-hospitalization, } \\
1 \quad \text { in case of one re-hospitalization, } \\
2 \quad \text { in case of at least two re-hospitalizations. }
\end{array}\right.
$$

Such variables as age, sex, type of cardiovascular disease and diabetes co-morbidity will be used. In addition, the co-existence of cardiovascular disease which served as a secondary diagnosis will be taken into account. The variable is denoted by $D_{4}$ (it is equal to 0 in case of lack of co-existence of cardiovascular diseases other than the primary diagnosis, and 1 when at least one disease occurs). Age is considered as continuous variable $T_{2}$. The vector of variables will be denoted by $\mathbf{R}=\left(T_{1}, T_{2}, D_{1}, D_{2}, D_{3}, D_{4}, Z\right) \equiv\left(R_{1}, R_{2}, \ldots, R_{7}\right)$. Patients with hypertensive, atherosclerosis and ischemic heart disease constitute different subpopulations. For this reason, the risk of re-hospitalization is modelled separately for each type of disease. The models are built using the stepwise backward elimination method. The same results are obtained using the forward selection method. Significance of interactions and of regression coefficients are determined using the results of Wald tests (p-value $<0.01$ ). Model fitting is verified by values of deviation statistic/df $(D / d f)$, chi-square statistic/df $\chi^{2} / d f$ and the Akaike criterion (AIC). The significant results for regression coefficients in the subpopulation with hypertensive disease are shown in Table 3.

Table 3. The estimators of parameters for a model in the subpopulation with hypertensive disease

\begin{tabular}{|l|c|c|c|c|c|c|}
\hline \multicolumn{1}{|c|}{ Parameter $\beta$} & $\hat{\beta}_{j}$ & $\begin{array}{c}\text { Estimation } \\
\text { error }\end{array}$ & $\exp \left(\hat{\beta}_{j}\right)$ & \multicolumn{2}{c|}{$\begin{array}{c}p \text {-value } \\
\text { (chi-square } \\
\text { Wald test) }\end{array}$} & \multicolumn{2}{|c|}{$\begin{array}{c}\text { Confidence interval }(0.95) \\
\text { of } \exp \left(\hat{\beta}_{j}\right)\end{array}$} \\
\hline Constant1 $\left(\beta_{1}\right)$ & 1.938667 & 0.073271 & 6.949479 & 0.000000 & 6.019824 & 8.022703 \\
\hline Constant2 $\left(\beta_{2}\right)$ & 3.694919 & 0.141159 & 40.24232 & 0.000000 & 30.51604 & 53.06863 \\
\hline $\begin{array}{l}\text { Co-existence of } \\
\text { cardiovascular disease }\left(\beta_{3}\right)\end{array}$ & 0.230788 & 0.073194 & 1.259592 & 0.001616 & 1.091257 & 1.453895 \\
\hline
\end{tabular}

Source: Own elaboration using Statistica 10.0 .

In the case of hypertension diseases, diabetes does not influence the risk of re-hospitalization. Co-existence of other cardiovascular diseases increases the risk of re-hospitalization by $25.96 \%$. 


\section{7.

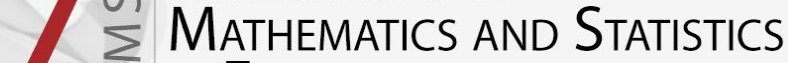 \\ IN ECONOMICS \\ International Scientific Conference | Poland • 27-31 August 2014}

A completely different situation is depicted in case of ischemic heart disease. Diabetes and age significantly affect the probability of re-hospitalization. All interactions proved to be insignificant. Significant results of the test for regression coefficient are provided in Table 4. Model fitting is assessed by value of $D / d f=0.501309, \chi^{2} / d f=0.991456$ and $\mathrm{AIC}=4889.01$.

Table 4. The estimators of parameters for a model in the subpopulation with ischemic heart disease

\begin{tabular}{|l|c|c|c|c|c|c|}
\hline \multicolumn{1}{|c|}{ Parameter $\gamma_{j}$} & $\hat{\gamma}_{j}$ & $\begin{array}{c}\text { Estimation } \\
\text { error }\end{array}$ & $\exp \left(\hat{\gamma}_{j}\right)$ & \multicolumn{2}{c|}{$\begin{array}{c}p \text {-value } \\
\text { (chi-square } \\
\text { Wald test) }\end{array}$} & \multicolumn{2}{|c|}{$\begin{array}{c}\text { Confidence interval }(0.95) \\
\text { of } \exp \left(\hat{\gamma}_{j}\right)\end{array}$} \\
\hline Constant1 $\left(\gamma_{j}\right)$ & 2.610330 & 0.240731 & 13.60354 & 0.000000 & 8.486758 & 21.80531 \\
\hline Constant2 $\left(\gamma_{2}\right)$ & 4.255729 & 0.250924 & 70.50821 & 0.000000 & 43.11745 & 115.2992 \\
\hline Age $\left(\gamma_{3}\right)$ & -0.015289 & 0.003260 & 0.984827 & 0.000003 & 0.978554 & 0.99114 \\
\hline Diabetes $\left(\gamma_{4}\right)$ & -0.206684 & 0.067046 & 0.81328 & 0.002051 & 0.299761 & 0.92749 \\
\hline
\end{tabular}

Source: Own elaboration using Statistica 10.0.

The probability that a patient will be re-hospitalized once is expressed by the following formula

$$
P(Y=1 \mid \mathbf{R}=\mathbf{r})=P(Y \leq 1 \mid \mathbf{R}=\mathbf{r})-P(Y=0 \mid \mathbf{R}=\mathbf{r}),
$$

where $P(Y \leq 1 \mid \mathbf{R}=\mathbf{r})=\frac{\exp \left(\gamma_{2}+\gamma_{3} r_{2}+\gamma_{4} r_{7}\right)}{1+\exp \left(\gamma_{2}+\gamma_{3} r_{2}+\gamma_{4} r_{7}\right)}$ and $P(Y=0 \mid \mathbf{R}=\mathbf{r})=\frac{\exp \left(\gamma_{1}+\gamma_{3} r_{2}+\gamma_{4} r_{7}\right)}{1+\exp \left(\gamma_{1}+\gamma_{3} r_{2}+\gamma_{4} r_{7}\right)}$

Relative risk connected with one re-hospitalization for diabetics and no-diabetics is given by

$$
R R_{(Y=1)}=\frac{P\left(Y=1 \mid R_{2}=r_{2}, R_{7}=1\right)}{P\left(Y=1 \mid R_{2}=r_{2}, R_{7}=0\right)} .
$$

The probability that a patient is re-hospitalized at least twice is presented in the following way

$$
P(Y=2 \mid \mathbf{R}=\mathbf{r})=1-P(Y \leq 1 \mid \mathbf{R}=\mathbf{r}) .
$$

Relative risk connected with at least two re-hospitalizations is calculated in a similar way as (11) and it is expressed by

$$
R R_{(Y=2)}=\frac{P\left(Y=2 \mid R_{2}=r_{2}, R_{7}=1\right)}{P\left(Y=2 \mid R_{2}=r_{2}, R_{7}=0\right)} .
$$

Values of relative risk (11) and (13) according with age are provided in Figure 1. Diabetes increases the risk of re-hospitalization. This risk decreases with age. Proportion of hospitalization expenditures in connection with the impact of diabetes on re-hospitalization risk (calculated by using (8)) varies from $12.7 \%$ to $18.32 \%$.

In the subpopulation of patients with atherosclerosis, diabetes increases the risk of rehospitalization only for women. In order to facilitate the interpretation, the variable sex is recoded ( 1 for women, 0 for men). Significant results for regression coefficients in the subpopulation with atherosclerosis are shown in Table 5. Model fitting is assessed by value of $D / d f=0.740761, \chi^{2} / d f=0.999349$ and $\mathrm{AIC}=18646.8$. 


\section{Am Amanconos of \\ Mathematics and Statistics \\ IN ECONOMICS}

International Scientific Conference | Poland • 27-31 August 2014

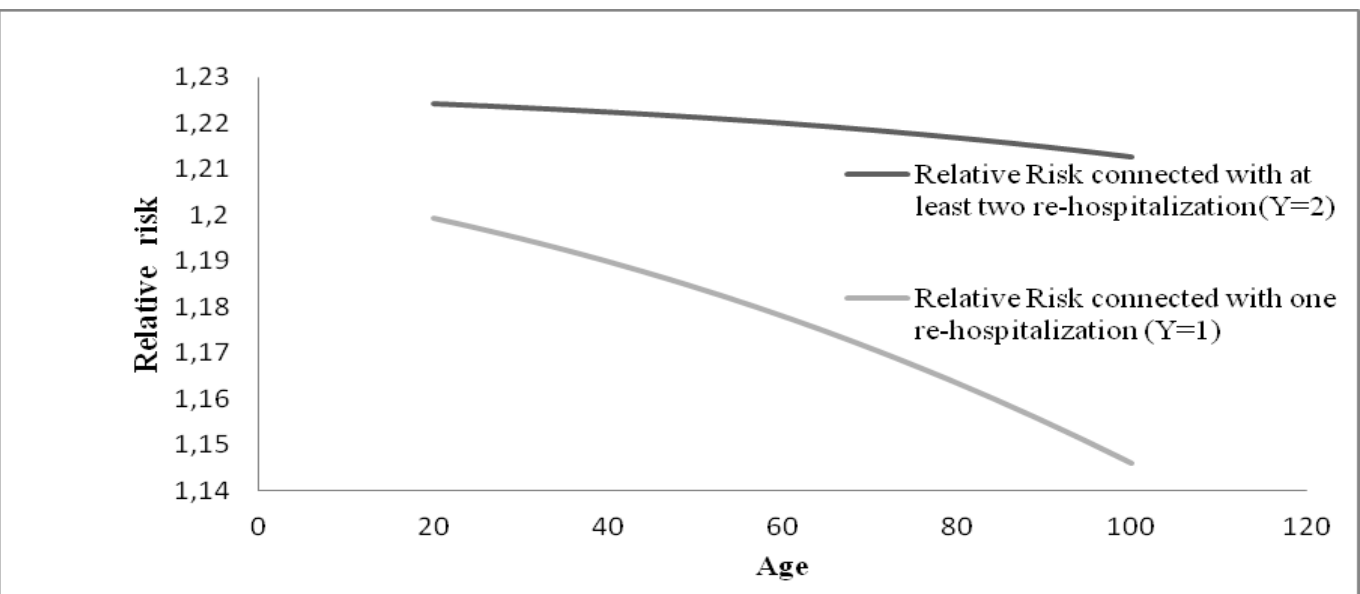

Figure 1. The relative risk connected with one and at least two re-hospitalizations in the population with ischemic heart disease.

Source: Own elaboration.

Relative risks connected with one and at least two re-hospitalizations of diabetics and nodiabetics in population women are calculated in analogous manner to (11) and (13) taking into account the values from table 5. The risk increases with age. Values of relative risks according to age are presented in Figure 2.

Table 5. The estimators of parameters for a model in the subpopulation with atherosclerosis

\begin{tabular}{|l|c|c|c|c|c|c|}
\hline Parameter $\delta_{j}$ & $\hat{\delta}_{j}$ & $\begin{array}{c}\text { Estimation } \\
\text { error }\end{array}$ & $\exp \left(\hat{\delta}_{j}\right)$ & $\begin{array}{c}p \text {-value } \\
\text { (chi-square } \\
\text { Wald test) }\end{array}$ & \multicolumn{2}{|c|}{$\begin{array}{c}\text { Confidence interval }(0.95) \\
\text { of } \exp \left(\hat{\delta}_{j}\right)\end{array}$} \\
\hline Constant2 $\left(\delta_{1}\right)$ & 1.756466 & 0.128293 & 5.791931 & 0.000000 & 4.504226 & 7.447776 \\
\hline Sex $\left(\delta_{2}\right)$ & -0.097162 & 0.032113 & 0.907409 & 0.000000 & 0.852056 & 0.966357 \\
\hline Sex $*$ Diabetes $\left(\delta_{3}\right)$ & -0.092064 & 0.031595 & 0.912047 & 0.000003 & 0.857281 & 0.97031 \\
\hline Age $\left(\delta_{4}\right)$ & 0.011185 & 0.001807 & 1.011248 & 0.002051 & 1.007673 & 1.014835 \\
\hline
\end{tabular}

Source: Own elaboration using Statistica 10.0.

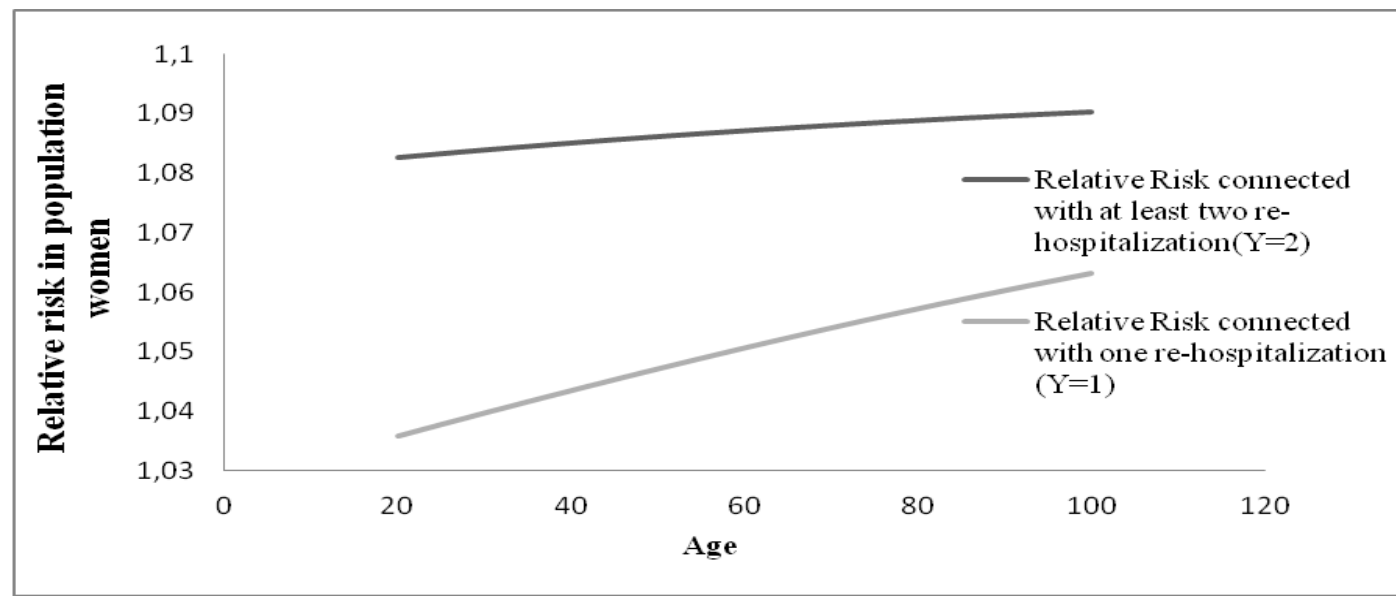

Figure 2. The relative risk connected with one and at least two re-hospitalizations in the population of women with atherosclerosis.

Source: Own elaboration. 
Proportion of hospitalization expenditures in connection with the impact of diabetes on rehospitalization risk (obtained by using (8)) varies from $3.46 \%$ to $8.28 \%$ depending on age.

\section{Conclusion}

The impact of diabetes on other diseases treatment cost is reflected directly in the surplus of cost for diabetics relative to non-diabetics. Diabetes also affects the cost of treatment indirectly by increasing the risk of hospitalization and re-hospitalization. The impact of diabetes on the risk of hospitalization due to hypertensive, ischemic heart disease and atherosclerosis is presented in the paper.

Determination of areas in which diabetes generates costs may be useful for the effective reallocation of public funds for the health care. This type of analysis can be helpful in determining for which diseases prevention programs should be carried out and how to set priorities in relation to financing specific medical procedures.

\section{Acknowledgements}

The research project "THE METHODOLOGY OF DEVELOPING SYSTEM OF QUALITY MEASURES OF MEDICAL SERVICES DELIVERED BY HOSPITALS" was financially supported by National Science Centre, Poland, on the base of the decision number DEC2011/01/B/HS4/05924.

\section{References}

1. BENICHOU J. 2007. Biostatistics and Epidemiology: Measuring the Risk Attributable to an Environmental or Gentic Factor, Comptes Rendus Biologies, Vol. 330, pp. 281-298.

2. Database from National Health Fund concerning unit hospitalizations in Lower Silesia, 2012.

3. HY X., XIE M., GOH TN, 2014, Objective Bayes Analysis of Zero-Inflated Poisson Distribution with Application to Healthcare Data, Operation Research \& Management Science, Vol. 46, pp. 843-852.

4. IDF Diabetes Atlas, Sixth Edition, 2013 (website: www.idf.org; cit. 01.02.2014).

5. JANKOWSKI W. et al. 2012. Analiza zmian społeczno-demograficznych oraz wpływu złego odżywiania, niedostatecznej aktywności fizycznej, nałogów i innych czynników ryzyka na rozpowszechnienie oraz koszty cukrzycy i chorób sercowo-naczyniowych w Polsce, (website: http://zdrowepokolenia.org/aktualnosci/raport-kpmg; cit. 01.04.2013).

6. KOZYRA C., ZMYŚLONA B. 2012. Morbidity, Mortality and Health Expenditures from Diabetes in Poland and in the other European Union Countries, Pragmata tes Oikonomias, Zeszyt VI, 2012, pp. 61-77.

7. LIM, H., LI, W., YU P. 2014. Zero-inflated Poisson regression mixture model, Computational Statistics \& Data Analysis, Vol.71, pp. 151-158.

8. LIU I., AGRESTI A. 2005. The Analysis of Ordered Categorical Data: An Overview and a Survey of Recent Developments, Statistics \& Probability, Vol. 14, pp. 1-30.

9. Yearbook of Polish Central Statistical Office 2011 (website: www.stat.gov.pl,).

10. ZAMANI, H., ISMAIL N., 2014. Functional Form for the Zero-Inflated Generalized Poisson Regression Model, Communications in Statistics - Theory and Methods, Vol. 43, pp. 515-529.

11. ZMYŚLONA, B., Application of Models for Binary Variable and Count Data to Estimation of Relative and Attributable Risk. Manuscript. 